3 Tolman JA, Wiederhold NP, McConville JT, et al. Inhaled voriconazole for prevention of invasive pulmonary aspergillosis. Antimicrob Agents Chemother 2009; 53: 2613-2615.

4 Tolman JA, Nelson NA, Son YJ, et al. Characterization and pharmacokinetic analysis of aerosolized aqueous voriconazole solution. Eur J Pharm Biopharm 2009; 72: 199-205.

5 Crandon JL, Banevicius MA, Fang AF, et al. Bronchopulmonary disposition of intravenous voriconazole and anidulafungin given in combination to healthy adults. Antimicrob Agents Chemother 2009; 53: 5102-5107.

6 Weiler S, Fiegl D, MacFarland R, et al. Human tissue distribution of voriconazole. Antimicrob Agents Chemother 2011; 55: 925-928.
7 Tolman JA, Nelson NA, Bosselmann S, et al. Dose tolerability of chronically inhaled voriconazole solution in rodents. Int J Pharm 2009; 379: 25-31.

8 Morrow PE. Conference on the scientific basis of respiratory therapy. Aerosol therapy. Aerosol characterization and deposition. Am Rev Respir Dis 1974; 110: 88-99.

9 Brand P, Friemel I, Meyer T, et al. Total deposition of therapeutic particles during spontaneous and controlled inhalations. J Pharm Sci 2000; 89: 724-731.

\title{
Screening for diabetes mellitus in patients with OSAS: a case for glycosylated haemoglobin
}

\section{To the Editors:}

Obstructive sleep apnoea syndrome (OSAS) is a highly prevalent disorder, associated with decreased quality of life, increased risk of road traffic accidents, and increased cardiovascular morbidity and mortality [1]. OSAS also appears to independently predict metabolic dysfunction, with a growing body of evidence suggesting that sleep disordered breathing may be an independent driver of insulin resistance and dysglycaemia [2]. Indeed, a particularly intimate relationship exists between obesity and the development of OSAS and type 2 diabetes mellitus (T2DM): in the Sleep Heart Health Study over half of the diabetic subjects studied had some degree of sleep disordered breathing, while $23.8 \%$ had a respiratory disturbance index in the moderate or severe range [3]. Similarly, up to $40 \%$ of subjects with OSAS are diabetic at diagnosis [4]. Identification of subjects with T2DM allows the introduction of appropriate treatment to reduce cardiovascular morbidity and diabetes-related mortality.

While screening for T2DM has conventionally utilised either fasting plasma glucose (FPG) measurement or performance of an oral glucose tolerance test (OGTT), glycosylated haemoglobin $(\mathrm{HbA1c})$ measurement has recently been approved as a stand-alone diagnostic test for T2DM by the American Diabetes Association (ADA) [5]. Furthermore, emerging data suggests $\mathrm{HbA} 1 \mathrm{c}$ is an independent predictor of both the development of T2DM and long-term cardiovascular mortality in non-diabetic subjects [6]. Hence, measurement of $\mathrm{HbA} 1 \mathrm{c}$ in OSAS patients not only facilitates screening for T2DM but may also allow identification of subjects at risk of subsequent metabolic and cardiovascular morbidity. We sought to assess the comparative utility of FPG and $\mathrm{HbA1c}$ in the identification of subjects with T2DM and impaired glucose tolerance (IGT) in a cohort with newly diagnosed OSAS.

We prospectively assessed consecutive subjects with newly diagnosed OSAS attending our sleep laboratory (St Vincent's University Hospital, Dublin, Ireland). Patients were excluded if they had a previous diagnosis of T2DM based on the medical history as reported by the patient, or the use of oral hypoglycaemic medications or insulin. Bloods were drawn in the morning following an overnight fast. Measurements of $\mathrm{HbA1c}$ and FPG were compared in the diagnosis of T2DM and IGT. HbA1c of $\geqslant 6.5 \%$ was considered consistent with T2DM as per ADA guidelines, while a level of 6-6.5\% was considered analogous to IGT, in keeping with recent evidence. FPG of $\geqslant 7 \mathrm{mmol} \cdot \mathrm{L}^{-1}\left(126 \mathrm{mg} \cdot \mathrm{dL}^{-1}\right)$ or $5.6-6.9 \mathrm{mmol} \cdot \mathrm{L}^{-1}$ (100-125 $\left.\mathrm{mg} \cdot \mathrm{dL}^{-1}\right)$ were considered consistent with T2DM and IGT, respectively. Fisher's exact test was used for statistical comparisons, with a p-value of $<0.05$ considered significant.

269 individuals were evaluated. 23 (8.5\%) had an antecedent diagnosis of T2DM, and were excluded from the analysis. Of the remaining 246 subjects, the majority were male, $<65$ yrs of age and obese. $39.7 \%$ had severe OSAS, with an overall mean apnoea/hypopnoea index (AHI) of 32.2 events $\cdot \mathrm{h}^{-1}$. Patient characteristics are summarised in table 1. $29(12 \%)$ subjects had $\mathrm{HbA} 1 \mathrm{c}$ of $>6.5 \%$, consistent with a diagnosis of T2DM. Only $14(5.5 \%)$ of the patients were identified as diabetic using FPG ( $p=0.025$ for comparison) (fig. 1). 66 $(27 \%)$ subjects had $\mathrm{HbA} 1 \mathrm{c}$ of $6-6.5 \%$, indicative of increased cardiovascular risk and predictive of future diabetes. FPG identified only $31(13 \%)$ individuals with IGT $(p=0.0001$ for comparison). Conversely, FPG identified one ( $0.4 \%)$ diabetic subject and $17(6.9 \%)$ additional individuals with IGT not identified by use of $\mathrm{HbA1c}$ alone. Patients with T2DM or IGT were older (mean age 51.9 versus 47.1 yrs), more obese (mean body mass index (BMI) 36.3 versus $33.6 \mathrm{~kg} \cdot \mathrm{m}^{-2}$ ), and had more severe OSAS (mean AHI 40.3 versus 29.2 events $\cdot \mathrm{h}^{-1}$ ) than those without. No significant sex differences were observed.

$\mathrm{HbA1c}$ has only recently been recommended as an appropriate stand-alone diagnostic test for T2DM by the most recent report of the Expert Committee on the Diagnosis and Classification of Diabetes Mellitus [7]. Its diagnostic utility had been questioned prior to this report, principally due to a lack of assay standardisation, leading to inter-centre variability, but recent years have seen the implementation of rigorous standardisation via the National Glycohemoglobin Standardization 


\begin{tabular}{|c|c|}
\hline TABLE 1 Patient C & \\
\hline Age yrs & $48.9 \pm 11.2$ \\
\hline Aged $<65$ yrs & 91 \\
\hline Male & 77.4 \\
\hline $\mathrm{BMI} \mathbf{k g} \cdot \mathrm{m}^{-2}$ & $34.9 \pm 6.9$ \\
\hline Waist circumference $\mathrm{cm}$ & $111.2 \pm 18.5$ \\
\hline Neck circumference $\mathbf{c m}$ & $42 \pm 4.3$ \\
\hline Obese & 76.2 \\
\hline Mild (BMI 30-34.9) & 29.7 \\
\hline Moderate (BMI 35-39.9) & 25.1 \\
\hline Severe $(B M I \geqslant 40)$ & 21.3 \\
\hline \multicolumn{2}{|l|}{ OSAS severity } \\
\hline Mild (AHI 5-14.9) & 28.5 \\
\hline Moderate (AHI 15-29.9) & 31.8 \\
\hline Severe $(A H I \geqslant 30)$ & 39.7 \\
\hline AHI events $\cdot h^{-1}$ & $32.2 \pm 24$ \\
\hline Mean $S_{p}, \mathrm{O}_{2} \%$ & $93.5 \pm 2.2$ \\
\hline Cholesterol $\mathrm{mmol} \cdot \mathrm{L}^{-1}$ & $4.8 \pm 1.0$ \\
\hline LDL-C mmol. $\mathrm{L}^{-1}$ & $2.85 \pm 0.88$ \\
\hline $\mathrm{HDL}-\mathrm{C} \mathrm{mmol} \cdot \mathrm{L}^{-1}$ & $1.47 \pm 5.50$ \\
\hline Triglycerides $\mathrm{mmol} \cdot \mathrm{L}^{-1}$ & $1.83 \pm 1.23$ \\
\hline Glucose $\mathrm{mmol} \cdot \mathrm{L}^{-1}$ & $5.7 \pm 1.03$ \\
\hline HbA1c \% & $5.95 \pm 1.29$ \\
\hline
\end{tabular}

Data are presented as mean \pm SD or $\%$. BMI: body mass index; OSAS: obstructive sleep apnoea syndrome; $\mathrm{AHI}$ : apnoea/hypopnoea index; $\mathrm{Sp}, \mathrm{O}_{2}$ : arterial oxygen saturation measured by pulse oximetry; LDL-C: low-density lipoprotein cholesterol; HDL-C: high-density lipoprotein cholesterol; HbA1c: glycosylated haemoglobin.

Program [8]. Measurement of $\mathrm{HbA1c}$ offers a number of advantages over FPG, including greater convenience and reduced day-to-day variability. Recent data from a large population of non-diabetic subjects followed longitudinally for a median of 14 yrs showed $\mathrm{HbA1c}$ to be as accurate a predictor of future T2DM as, and a better predictor of future cardiovascular illness and death than, FPG [6].

Consistent with previous reports, we found a strikingly high prevalence of undiagnosed T2DM and IGT in a group of newly diagnosed OSAS patients. However, using FPG as a lone screening modality would have failed to identify more than half of these individuals. Furthermore, measurement of $\mathrm{HbA} 1 \mathrm{c}$ permits the identification of a large group of subjects with sleep disordered breathing who may be at increased risk of developing overt T2DM and significant cardiovascular morbidity, a group that may warrant closer medical supervision in succeeding years.

Current expert consensus guidelines suggest OSAS patients should be screened for T2DM using FPG, with the addition of OGTT where warranted [9]. Although clearly of limited utility in patients with anaemia and haemoglobinopathies [5], we would suggest that our data support the use of $\mathrm{HbA} 1 \mathrm{c}$ as an effective, convenient and inexpensive screening tool in individuals newly diagnosed with sleep disordered breathing. Our data suggest screening is particularly relevant in older, more obese subjects with more severe sleep disordered breathing.

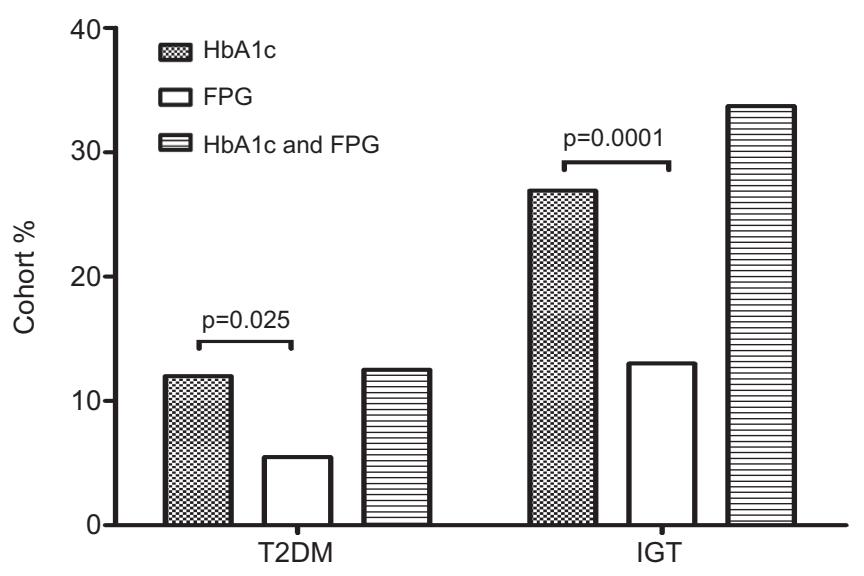

FIGURE 1. Prevalence of type 2 diabetes mellitus (T2DM) and impaired glucose tolerance (IGT) as detected by measurement of glycosylated haemoglobin ( $\mathrm{HbA} 1 \mathrm{c})$ and fasting plasma glucose (FPG) in an obstructive sleep apnoea syndrome cohort.

\section{Deirdre B. Fitzgerald*, Brian D. Kent ${ }^{*, \#,}$ John F. Garvey*\#, Audrey Russell*, Geraldine Nolan* and Walter T. McNicholas*,\#}

*Pulmonary and Sleep Disorders Unit, St Vincent's University Hospital, and "School of Medicine and Medical Science, University College Dublin, Dublin, Ireland.

Correspondence: W.T. McNicholas, Pulmonary and Sleep Disorders Unit, St Vincent's University Hospital, Elm Park, Dublin 4, Ireland. E-mail: walter.mcnicholas@ucd.ie

Statement of Interest: None declared.

\section{REFERENCES}

1 McNicholas WT, Bonsigore MR. Management Committee of EU COST ACTION B26. Sleep apnoea as an independent risk factor for cardiovascular disease: current evidence, basic mechanisms and research priorities. Eur Respir J 2007; 29: 156-178.

2 Lam JCM, Lam B, Yao TJ, et al. A randomised controlled trial of nasal continuous positive airway pressure on insulin sensitivity in obstructive sleep apnoea. Eur Respir J 2010; 35: 138-145.

3 Resnick HE, Redline S, Shahar E, et al. Diabetes and sleep disturbances: findings from the Sleep Heart Health Study. Diabetes Care 2003; 26: 702-709.

4 Meslier N, Gagnadoux F, Giraud P, et al. Impaired glucose-insulin metabolism in males with obstructive sleep apnoea syndrome. Eur Respir J 2003; 22: 156-160.

5 American Diabetes Association. Diagnosis and classification of diabetes mellitus. Diabetes Care 2011; 34: Suppl. 1, S62-S69.

6 Selvin E, Steffes MW, Zhu H, et al. Glycated hemoglobin, diabetes, and cardiovascular risk in nondiabetic adults. N Engl J Med 2010; 362: 800-811.

7 International Expert Committee. International Expert Committee report on the role of the A1C assay in the diagnosis of diabetes. Diabetes Care 2009; 32: 1327-1334.

8 Little RR, Sacks DB. $\mathrm{HbA}(1 \mathrm{c})$ : what do the numbers really mean? Lancet 2011; 378: 1068-1069.

9 Shaw JE, Punjabi NM, Wilding JP, et al. Sleep-disordered breathing and type 2 diabetes: a report from the International Diabetes Federation Taskforce on Epidemiology and Prevention. Diabetes Res Clin Pract 2008; 81: 2-12. 